\title{
Review: community mental health team management for adults with severe mental illnesses increases satisfaction with care
}

Tyrer P, Coid J, Simmonds S, et al. Community mental health team management for those with severe mental illnesses and disordered personality. In:Cochrane Database of Systematic Reviews. The Cochrane Library. Oxford: Update Software, 1997: issue 4.

\section{Objective}

To evaluate the effect of community mental health team (CMHT) management compared with standard non-team care on adults who present to psychiatric services with any diagnosis of severe mental illness.

\section{Data sources}

Studies were identified using Biological Abstracts (1982 to January 1997), Cochrane Library, Cochrane Schizophrenia Group's Register of trials, EMBASE (1980 to January 1997), Medline (1966 to January 1997), PsycLIT (1974 to January 1997), and SCISEARCH databases; bibliographies of relevant papers; hand searches of the Journal of Personality Disorders; and contact with authors and colleagues in community and forensic psychiatry.

\section{Study selection}

Studies were selected if they were randomised or quasirandomised controlled trials; included participants who had any diagnosis of severe mental illness and compared CMHT management (a multidisciplinary, community team which together assesses participants, prescribes and monitors medication, provides psychological interventions, and focuses on continuity of care) with standard care from hospital based staff who were not part of a team.

\section{Data extraction}

Data were extracted by 2 reviewers on deaths, suicides, dropouts, admission to hospital, general improvement in symptoms, participant and relative satisfaction, and family burden.

\section{Main results}

4 randomised controlled trials met the inclusion criteria. All studies were run in inner cities: 2 in the UK, 1 in Canada, and 1 in Australia. In each study, most participants had a diagnosis of schizophrenia and a history of psychiatric illness; a minority had neurotic disorders. CMHT management led to fewer participants dropping out (4 studies, $\left.\{\mathrm{p}=0.004\}^{*}\right)$ and greater satisfaction with care for participants (2 studies, $\{\mathrm{p}<0.0001\} *)$ and relatives (1 study, $\left.\{\mathrm{p}<0.0001\}^{*}\right)$ than standard non-team care (table). Differences between treatments for deaths, suicides or deaths in suspicious circumstances, hospital admissions, clinically important changes in symptoms, and family burden were not statistically significant.

\section{Conclusion}

Community mental health team management reduces the dropout rate and leads to more satisfaction with care for adults who have severe mental illnesses and their relatives compared with standard non-team standard care.

*p values calculated using data in article.

Community mental health team (CMHT) management $v$ standard non-team care in adults with serious mental illnessest

\begin{tabular}{llllll}
\hline & $\begin{array}{l}\text { CMHT } \\
\text { Weighted } \\
\text { EER }\end{array}$ & $\begin{array}{l}\text { Standard } \\
\text { Weighted } \\
\text { CER }\end{array}$ & $\begin{array}{l}\text { RRR } \\
(95 \% \text { CI) }\end{array}$ & $\begin{array}{l}\text { Weighted } \\
\text { ARR }\end{array}$ & $\begin{array}{l}\text { NNT } \\
\text { (CI) }\end{array}$ \\
\hline Dropouts & $40 \%$ & $49 \%$ & $\begin{array}{l}25 \% \\
(11 \text { to } 36)\end{array}$ & $9 \%$ & $\begin{array}{l}11 \\
\text { (7 to 33) }\end{array}$ \\
$\begin{array}{c}\text { Participant not } \\
\text { satisfied with care }\end{array}$ & $39 \%$ & $65 \%$ & $\begin{array}{l}40 \% \\
\text { (21 to 54) }\end{array}$ & $26 \%$ & $\begin{array}{l}4 \\
\text { (3 to } 8)\end{array}$ \\
$\begin{array}{l}\text { Relative unsatisfied } \\
\text { with care }\end{array}$ & $35 \%$ & $78 \%$ & $\begin{array}{l}55 \% \\
\text { (36 to 70) }\end{array}$ & $43 \%$ & $\begin{array}{l}3 \\
\text { (2 to } 4)\end{array}$ \\
\hline
\end{tabular}

†Abbreviations defined in glossary; RRR, ARR, NNT, and CI calculated from data in article.

Source of funding:no external funding.

For article reprint: Professor P Tyrer, St Charles Hospital, Academic Department of Psychiatry, Exmoor Street, London W10 6DZ, UK. Fax +44 (0)171 8861994.

\section{Commentary}

Noteworthy in the review by Tyrer $e t$ al is the small amount of good quality evidence which was available, according to the inclusion criteria used in the study. Out of 70 citations rated as relevant to the review, only 4 studies met the inclusion criteria. Does this disappointing result explain why the current practice of psychiatry in most countries is moving too slowly towards a community based system of care? I do not believe that it does. However, it would be helpful for clinicians to see the results of analyses conducted on a larger number of studies which were selected using less rigid criteria.

The results of this review are encouraging. Clinicians will learn that CMHT management in inner cities (the most difficult context compared with rural areas) substantially decreases dropout rates, pro- duces greater satisfaction with care for service users and relatives, and may reduce suicide. A practice recommendation is that we should be more optimistic and launch more new programmes of CMHT treatment.

It is possible that advantages on other outcome measures may become statistically significant and clinically important over a longer follow up period. The hypothesis would be that the beneficial effect of CMHT management on those measures is largely indirect, and acts through a decrease in dropout rates and, therefore, relapse rates. A key feature of community based mental health care is to ensure continuity of care to most patients who are disabled and severely ill, and it is widely believed that continuity decreases dropout and relapse rates. More specific research is needed on this topic.

Another important issue arising from the review is the need to find a consensual working definition of "severe mental illness". Future controlled trials should not only include longer follow up but should also focus on more clearly defining what severely mentally ill means to ensure comparability between studies.

Finally, there is the need to identify the basic constituents of effective community team management. What are the factors that really matter? The authors enumerate 5 factors. They should be operationally defined to be tested properly by researchers and considered by clinicians in their everyday practice.

Michele Tansella, MD Università di Verona Verona, Italy 